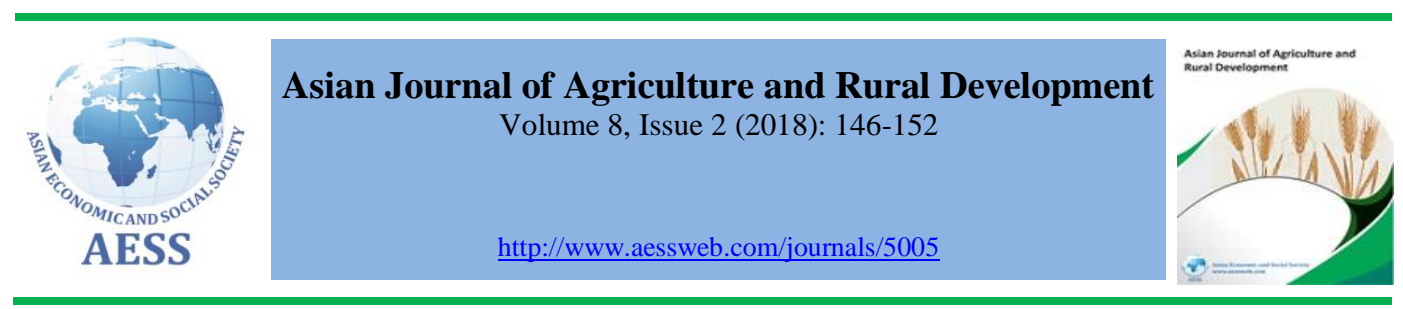

\title{
ASSESSMENT OF PRODUCE STANDARDIZATION ADOPTED BY THE RICE FARMERS IN THE MARKETING OF THEIR RICE PRODUCE IN EBONYI STATE, NIGERIA
}

\section{J. C. Mgbanya ${ }^{a}$}

A. V. Eze

C. C. Obiora ${ }^{\text {a }}$ a Department of Agribusiness and Management, Michael Okpara University of Agriculture Umudike, Abia State, Nigeria

b Department of Agribusiness Management and Trade, Kenyatta University, Nairobi, Kenya

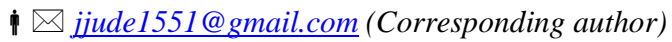

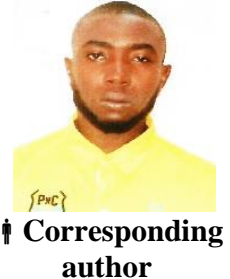

author

\section{ARTICLE HISTORY:}

Received: 06-Sep-2018

Accepted: 21-Dec-2018

Online Available: 07-Jan2019

\section{Keywords:}

Assessment,

Produce standardization,

Rice farmer Marketers,

Ebonyi State,

Nigeria

\begin{abstract}
The study assessed the produce standardization adopted by the rice farmers in the marketing of their rice produce in Ebonyi State, Nigeria. Multistage and random sampling techniques were employed in selecting 120 samples. Data were collected using structured questionnaire. Data obtained were analysed using descriptive statistics. The result obtained shows that the farmers sort and grade their produce according to: size (33.33\%), anomalies $(8.33 \%)$, shapes and appearance $(25 \%)$. The result further showed that the packaging materials used by the farmers were: sack $(100 \%)$, while the unit of measurement standard used by the farmer comprises of: unmeasured $50 \mathrm{~kg}$ sack $(95 \%)$ and unmeasured $100 \mathrm{~kg}$ sack $(88.33 \%)$. The result from the analysis of the social and economic effects of standard measures adopted by the farmer marketers include: misrepresentation of the product features and pricing $(\mathrm{Xi}=4.52)$, misrepresentation of the quantity measurement $(\mathrm{Xi}=4.05)$, etc. The ascertained constraints to rice produce standardization in Ebonyi state includes: lack of participation of Ebonyi state rice farmers in standard setting forums both at national and international level $(\mathrm{Xi}=2.89)$. The study strongly recommends that the farmers should use weighing balance during marketing of their sorted and graded rice produce.
\end{abstract}

\section{Contribution/ Originality}

This study will help to educate the farmers, NGOs, governments, marketers, standard setting organizations the nature of rice standardization adopted by the rice farmer marketers in Ebonyi state and also the constraints to rice produce standardization in the study area. It will also guide the use of improved standards in rice produce marketing in particular and agricultural produce at large.

DOI: 10.18488/journal.1005/2018.8.2/1005.2.146.152

ISSN (P): 2304-1455/ISSN (E):2224-4433

How to cite: J. C. Mgbanya, A. V. Eze and C. C. Obiora (2018). Assessment of produce standardization adopted by the rice farmers in the marketing of their rice produce in Ebonyi state, Nigeria. Asian Journal of Agriculture and Rural Development, 8(2), 146-152.

() 2018 Asian Economic and Social Society. All rights reserved. 


\section{INTRODUCTION}

In Nigeria, empirical studies have reported that Ebonyi state is known to be farming rice on 81,000 hectares out of 1,788,200 hectares of national rice cultivatable land (National Bureau of Statistics, 2011). In addition, Ebonyi state is ranked the third largest producers of rice $(244,160 \mathrm{MT})$ after Taraba and Benue State (National Agricultural Extension and Research Liaising Services and Project Coordinating Unit, 2006). Pertinently, rice farming and marketing contributes significantly in ensuring food security, poverty alleviation, employment and growth in Gross Domestic Product (GDP) of Nigeria (International Rice Research Institute, 2016).

However, one of the essences of rice production is to distribute the produce to the marketers due to the fact that rice is one of the utmost essential foods consumed in Nigeria. This is further confirmed by Onoja and Herbert (2012) study which reported that 50\% of the world population is wholly dependent on rice as a staple food. This produce is to be marketed according to a set standard in regard to the uniform sorting, grading, measurement, presentation and packaging. Though, standards are refer to as documents, established by consensus and approve by a recognized body that provide, for common and repeated use, rules, guidelines or characteristics for produce/products or related process and production methods (Margret and Dovis, 2007). Likewise, product standardization is refers to as uniform representations of all aspects of the product such as the quality, the materials been used, product name and packaging for all markets, regardless of location around the world (Doole and Lowe, 2008). According to John (2002) standardized commodities makes possible lower cost of production, processing and marketing, then places some restriction on consumer choice. This is why the Codex Alimentarius Commission (CAC) stated that only standardized commodities are suitable for being traded on the forward and future market (Margret and Dovis, 2007). United Nations Conference on Trade and Development (UNCTAD) (2007) stated that in order to harmonize standards and coordinate joint efforts by public and private bodies, the Codex Alimentarius Commission (CAC) of the United Nation should be taken as the main reference and common basis for food standards.

Despite the important of product standardization, the Standards Organization of Nigeria (SON) in collaboration with other stakeholders are yet to set a policy concerning the use of standards in the marketing of rice commodity in the market place. Meanwhile, Ayinde et al. (2009) posited that increase in farm output has not led to a corresponding increase in the earnings of the vast majority of farmers. One of the factors emphasized as being responsible is due to standard inefficiency, huge importation, and high rate of spoilage and lack of storage facilities.

Therefore, since the prospect for marketing rice produce in Ebonyi state is enormous, there is need to assess the following specific objectives; identify the produce standardization adopted by the rice farmers in the marketing of their rice produce; ascertain the social and economic effects of standards adopted in the marketing of rice, and ascertain the constraints to the standardization of rice produce marketing in the study area.

\section{METHODOLOGY}

The study was conducted in Ebonyi State in south eastern part of Nigeria. The state is situated between latitudes $5^{\circ} 40^{1}$ and $6^{\circ} 54^{1} \mathrm{~N}$ and longitudes $7^{\circ} 30^{1}$ and $8^{\circ} 30^{1} \mathrm{E}$. Statistic from 2006 census indicates that the area has a total population of 2, 176, 947 people, with a growth rate of $3.5 \%$ per annum (National Bureau of Statistics, 2011). The area which is predominantly agrarian has the major staple food crops grown as yam, cassava, cocoyam, potatoes, rice, groundnut, maize, and vegetables. The study adopted multistage and random sampling techniques. Three (3) local government areas were randomly selected from the three zones of the state. In the second stage, two (2) communities were randomly selected from the three local government areas there by making it six (6) communities. In the third stage, two villages were randomly selected from the six 
communities, thereby making a total of 12 villages. In the fourth stage, ten (10) rice farmers were randomly selected from the two villages to give a total sample size of 120 for the study. Data were collected from the sampled rice farmers using structured questionnaire. Descriptive statistical tool such as frequency, percentage and Likert scale were used to analyse the data obtained from the study. The model for the mean score analysis is represented as;

$$
X_{i}=\frac{\sum_{j=1}^{n} X_{i} N_{i}}{N_{r}}
$$

Where

$\mathrm{X}_{\mathrm{i}}=$ Mean score

$\sum=$ Summation

$\mathrm{X}_{\mathrm{j}}=$ Likert value

$\mathrm{N}_{\mathrm{j}}=$ Number of respondents that choose that Likert value (Frequency that selected the same Likert value)

$\mathrm{N}_{\mathrm{r}}=$ Total Number of respondents.

\subsection{Decision rule}

Accept for mean score $>3.0$ and $>2.5$ otherwise reject; for five and four point Likert Scale Rating respectively.

\subsection{Justification}

For 5-point Likert scale, if the scale range is $1=$ strongly disagree, $2=$ disagree, $3=$ somehow agree, $4=$ agree and $5=$ strongly agree, then $1+2+3+4+5=15$, therefore the mean of the 5 point scale will be the total sum of the scale range which is 15 divided by the Likert scale point which is 5 . This will give $15 / 5=3,3$ becomes the average score and point of decision rule. Therefore any mean score of each factor that is greater than or equal to 3 shows that the respondents somehow agrees or agrees or strongly agree that the factor has effect and vice versa. Moreover, for 4-point Likert scale, If the scale range is $1=$ strongly disagree, $2=$ disagree, $3=$ agree and $4=$ strongly agree, then $1+2+3+4=10$, therefore the mean of the 4 point scale will be the total sum of the scale range which is 10 divided by the Likert scale point which is 4 . This will give $10 / 4=2.5,2.5$ becomes the average score and point of decision rule. Therefore any mean score of each factor that is greater than or equal to 2.5 shows that the respondents agrees or strongly agree that the factor has effect and vice versa.

\section{RESULTS AND DISCUSSION}

\subsection{Produce standardization adopted in the marketing of rice produce by the rice farmers}

The result in table 1 shows the criteria selected in identifying the produce standardization adopted by the rice farmers in marketing their produce: sorting and grading, packaging and unit of measurement.

Table 1: Frequency distribution of produce standardization adopted in the marketing of rice produce by the rice farmers

\begin{tabular}{lcc}
\hline Produce Standardization Adopted & Frequency $(\mathbf{n = 1 2 0})$ & Percentage $(\boldsymbol{\%})$ \\
\hline Sorting and grading & & \\
Size & 40 & 33.33 \\
Anomalies & 10 & 8.33 \\
Shapes and appearance & 30 & 25 \\
Colour & 52 & 43.33 \\
Maturity & 90 & 75 \\
Variety/Taste & 45 & 37.5 \\
Packaging & & \\
\hline
\end{tabular}




\begin{tabular}{lcc}
\hline Sack & 120 & 100 \\
Units of Measurement & 32 & 26.7 \\
Kilogram & 114 & 95 \\
Unmeasured 50kg sack & 106 & 88.33 \\
Unmeasured 100kg sack & & \\
\hline
\end{tabular}

Field survey, 2016

The result showed that the sorting and grading standards adopted by the farmers in marketing their rice produce include: size $(33.33 \%)$, anomalies $(8.33 \%)$, shapes and appearance $(25 \%)$, colour $(43.33 \%)$, maturity $(75 \%)$, variety/taste $(37.5 \%)$. The result further showed that the packaging materials used by the farmers were: sack $(100 \%)$, while the unit of measurement standard used by the farmer comprises of: kilogram (26.7\%), unmeasured 50kg sack $(95 \%)$ and unmeasured $100 \mathrm{~kg}$ sack $(88.33 \%)$. This implies that among the product standards criteria adopted by the rice farmers in the marketing of their produce; greater percentage of rice farmers sort and grade their produce according to maturity. Few farmers take cognizance of sorting their produce according to size, colour, shapes and varieties/taste, thereby showing that greater percentage of rice farmers sale their produce without sorting and grading. The result also implies that the entire farmers package their rice produce with sack before selling, and more percentage do not weigh the rice produce with weighing scale before selling. This is why Omotesho et al. (1995) reported that there are various units of measurements of grain available in the markets and that the unit of measurement not only varies from market to market but from marketer to marketer. They also cited Adekanye who observe that there were no standardized measures of quality and quantity in Nigeria food stuff markets.

\subsection{Social and economic effects of produce standards adopted in the marketing of rice}

Table 2 shows the result of the analysis of social and economic effects of measures adopted in the marketing of rice by the rice farmers.

Table 2: Mean score analysis on social and economic effects of produce standards adopted in the marketing of rice

\begin{tabular}{lcc}
\hline Effects of measures adopted & Mean score & Decision \\
\hline Social & & \\
Misrepresenting the product & & \\
features and pricing & 4.52 & Accepted \\
High pressure selling & 3.89 & Accepted \\
Poor product quality & 4.39 & Accepted \\
Poor service & 4.11 & Accepted \\
Economic & & \\
Low pricing & 4.23 & Accepted \\
High selling powers & 2.19 & Rejected \\
Low choice preferences & 4.03 & Accepted \\
Misrepresentation of the quantity measurement & 4.05 & Accepted \\
Poor packaging and presentation & 4.4 & Accepted \\
Free market entry with any quality of rice & 3.79 & Accepted \\
produce at the domestic market & 2.85 & Rejected \\
Low in Technology progress & 3.79 & Accepted \\
No or little improvement on domestic standards & 3.98 & Accepted \\
No improvement on domestic storage facilities & & \\
\hline
\end{tabular}

Source: Field survey, 2016

Decision rule: Accept for mean score $>3.0$ otherwise reject 
The result as presented in Table 2 indicates that the produce standard measures adopted by the rice farmers in the marketing of rice produce have both social and economic implication on rice marketing. From the result, it was perceived that the social effects of the adopted standards have led to misrepresenting the product features and pricing $(\mathrm{Xi}=4.52)$, high pressure selling $(\mathrm{Xi}=$ $3.89)$, Poor product quality $(\mathrm{Xi}=4.39)$ and Poor service $(\mathrm{Xi}=4.11)$. The result further shows that the economic effects of the adopted standards have resulted to low pricing $(\mathrm{Xi}=4.23)$, low choice preference $(\mathrm{Xi}=4.03)$, misrepresentation of the measuring instruments $(\mathrm{Xi}=4.05)$, free market entry with any quality of commodities at the domestic market $(\mathrm{Xi}=3.79)$, no or little improvement on domestic standards $(\mathrm{Xi}=3.79)$ and no improvement on domestic storage facilities $(\mathrm{Xi}=3.98)$. This result is in line with Kotler and Armstrong (2013) who stated that on the social criticism of marketing; consumer advocates, government agencies, other critics have accused marketing of harming customers socially through, deceptive practices, high pressure selling, unsafe products, planned obsolescence and poor service to disadvantaged consumers. They also stated that nations vary greatly in their levels and distribution of income, thereby some developing economies also practice subsistence economies; consuming most of their own agricultural output and offering few to market opportunity. Likewise this result conforms to the findings of Yisa (2009) who stated that most of the measures adopted in the markets are susceptible to manipulation to change in volume, in an attempt to take advantage of the buyers, this is why quantities vary within markets, across markets and from time in the market place as he further stated.

\subsection{Constraints to rice produce standardization among rice farmers}

Mean score analysis was used to analyse the constraints needed to be mitigated by institutions that facilitates the standardization of agricultural commodities which is presented in Table 3 .

Table 3: Mean score analysis on the constraints to rice produce standardization among rice farmers

\begin{tabular}{|c|c|c|c|}
\hline Institution & Constraints & Mean Score & Decision \\
\hline \multirow[t]{5}{*}{$\begin{array}{l}\text { Political and Social } \\
\text { Institution }\end{array}$} & $\begin{array}{l}\text { Lack of participation of Ebonyi State rice } \\
\text { farmers in all standard setting forums both at } \\
\text { national and International level }\end{array}$ & 2.89 & Accepted \\
\hline & $\begin{array}{l}\text { Lack of policy framework that contain the } \\
\text { uniform standards and grading practice for rice } \\
\text { produce marketing in Ebonyi State }\end{array}$ & 2.9 & Accepted \\
\hline & $\begin{array}{l}\text { Poor implementation of trading policies that ban } \\
\text { importation of processed rice Produce }\end{array}$ & 3.11 & Accepted \\
\hline & $\begin{array}{l}\text { No restriction to the use of non-uniform } \\
\text { standards and grading practices during marketing } \\
\text { of rice produce }\end{array}$ & 3.01 & Accepted \\
\hline & $\begin{array}{l}\text { Inadequacy of infrastructural facilities That } \\
\text { supports development of standards and grading } \\
\text { practices for rice produce }\end{array}$ & 2.87 & Accepted \\
\hline \multirow{4}{*}{$\begin{array}{l}\text { Financial and } \\
\text { Economic Institution }\end{array}$} & Absence of bank funding to produce standards & 3.32 & Accepted \\
\hline & $\begin{array}{l}\text { High cost of compliance to a develop Standards } \\
\text { for small and medium sized enterprise }\end{array}$ & 2.48 & Rejected \\
\hline & $\begin{array}{l}\text { Lack of adoption of uniform Standardization and } \\
\text { grading practices }\end{array}$ & 3.56 & Accepted \\
\hline & $\begin{array}{l}\text { Inadequate promotion and sustaining of } \\
\text { marketing corporation by Nigeria fiscal, trade } \\
\text { and monetary policy }\end{array}$ & 2.63 & Accepted \\
\hline
\end{tabular}

Sources: Field survey, 2016

Decision Rule: Accept for mean score $\geq 2.5$ otherwise reject 
The result shows that the constraints to rice produce standardization were cause by inadequacy in these major institutions which were: political and social institutions and the financial and economic institutions. The inadequacy in political and social institution had led to: lack of participation of Ebonyi State rice farmers in standard setting forums both at national and international level $(\mathrm{Xi}=2.89)$, lack of policy framework that contain the uniform standards and grading practice for rice produce marketing in Ebonyi state $(\mathrm{Xi}=2.90)$, poor implementation of trading policies that ban importation of foreign rice $(\mathrm{Xi}=3.11)$, no restriction to the use of nonuniform standards and grading practices during marketing of rice produce $(\mathrm{Xi}=3.01)$, lack of infrastructural facilities that supports development of standards and grading practices for rice produce $(\mathrm{Xi}=2.87)$, While the meagerness in financial and economic institutions has resulted to: absence of bank funding and participation in developing produce standards $(\mathrm{Xi}=3.32)$, lack of adoption of uniform standardization and grading practices. $(\mathrm{Xi}=3.56)$, and Inadequate promotion and sustaining of marketing corporation by Nigeria fiscal, trade and monetary policy (Xi $=2.63$ ). Importantly, high cost of compliance to a develop standards for small and medium sized enterprise $(\mathrm{Xi}=2.48)$ was rejected. This result conforms to the following findings; policy instability is a major constraint to sustainable agricultural development in Nigeria (Idachaba, 2000). Marketing Corporations are established to coordinate the production, investments, grades and standards, market price stabilization for all value chain in Nigeria in order to facilitate marketing (Akinwumi, 2012). For Kenya to participate actively in the International Standard Organisation which gives access to world markets, in turn, contributes to economic growth, the following constraints need to be addressed; active participation in all standard setting forums, because the inability of African countries to participate in these meetings has turned most of the African nations into standard takers (Amwayi, 2009). He further opined that financial constraints coupled with limited capacity to provide credible information based on research needed to be articulated and the cost of compliance to this standards are high to be fully practiced by small and medium sized enterprise without help from financial and government policy. In addition, Jairath (2009) reported that lack of support infrastructures, lack of adoption of standardization and grading practices while selling agricultural commodities, Unorganized physical market, lack of awareness and information dissemination, absence of bank participation in commodity markets, etc are the major constraints faced by various commodity stakeholders in standardizing commodity in India.

The rejection of the high cost of compliance $(\mathrm{Xi}=2.48)$ to a develop standards for small and medium sized enterprise entails that when other constraints are controlled, high cost of compliance to a develop standards for small and medium sized enterprise will be minimized.

\section{CONCLUSION AND RECOMMENDATIONS}

The outcome of this study; assessment of produce standardization adopted by the rice farmers in the marketing of their rice produce in Ebonyi State Nigeria, revealed that the produce standardization adopted by the greater percentage of the rice farmer marketers include sorting and grading according to maturity, and packaging with sack bag without measuring with standard instrument to reflect the true weight. However the low percentage adoption of all forms of produce standardization by the marketers has resulted to some social and economic effects. Moreover, political, social, and economic institutions are the institutional factors that constrain farmer marketers from standardizing rice produce in the study area.

Therefore the study strongly recommend that the standard organization of Nigeria (SON) should design produce standards, train the farmers through the service providers on how to apply the standards in the marketing of their produce. The SON should also engage in restricting rice farmers from marketing non-standardize produce. The private firms in collaboration with government should encourage importation of sorting and grading machines. The farmer marketers should adopt the use of weighing balance in measuring their rice produce. 
Funding: This study received no specific financial support.

Competing Interests: The authors declared that they have no conflict of interests.

Contributors/Acknowledgement: First author designed the study, collected and arrange data, performed the statistical analysis and wrote the first draft of the study. Second author managed the analyses; third author participated in data collection and result discussion.

Views and opinions expressed in this study are the views and opinions of the authors, Asian Journal of Agriculture and Rural Development shall not be responsible or answerable for any loss, damage or liability etc. caused in relation to/arising out of the use of the content.

\section{Reference}

Akinwumi, A. (2012). Investing in Nigeria's agricultural value chains. Ministry of agricultural and rural development. Presented at the Bank of Industry's Nigerian Investment Forum, London. P 11. view at Google scholar

Amwayi, O. M. (2009). The role of ISO Standards in Kenya's economy. Kenya Bureau of Standards. Pp 8-9. view at Google scholar

Ayinde, O. E., Adewumi, M. O., \& Ojehomon, V. E. T. (2009). Determinants of technical efficiency and varietal gap of rice production in Nigeria. A meta-frontier model approach. Proceeding of the international association of agricultural economic conference, held at Beijing, China, August. Pp16-22. view at Google scholar

Doole, I., \& Lowe, R. (2008). International marketing strategy: Analysis development and implementation $5^{\text {th }}$ ed. London Thomson Learning. view at Google scholar

Idachaba, F. S. (2000). Workable and desirable agricultural policies for Nigeria in the first decade of the $21^{\text {st }}$ Century. The First in the Sense of Departmental Lectures on Tropical Issues in Nigeria Agriculture, Department of Agricultural Economics, University of Ibadan. view at Google scholar

International Rice Research Institute (2016). Rice Agri-food system CRP, rice. Proposal for a Rice Agri-Food System (RICE) CGIAR Research program. Submited to CGIAR Consrtium Office, C/O Agropolis International Avenue, France. Pp 1-118.

Jairath, M. S. (2009). Constraints, opportunities and options to improve Indian agricultural commodity futures market. Ind.jn. of Agric. Econ, 64(3), Pp 364. view at Google scholar

John, B. (2002). A dictionary of economics (2 ${ }^{\text {nd }} E d$.) Oxford University press. Available @ http://www.oxfordreference.com/view/10.1093/acref/9780199237043.001.0001/acref9780199237043-e-2957.

Kotler, P., \& Armstrong, G. (2013). Principles of marketing. Pearson Education (England) Ltd. Edinburgh Gate. Pp 589-597. view at Google scholar

Margret, W., \& Doris, G. (2007). Food quality and safety standards. ( $2^{\text {nd }}$ Edition) Available online at http://www.gtz.de

NAERLS \& PCU (2006). Field Situation assessment of 2006 wet season agricultural production in Nigeria. Pp 1-14.

NBS (2011). Annual abstract of statistics. Plot 762, Independence Avenue, Central Business District, Gariki, Abuja, Nigeria. view at Google scholar

Omotesho, O. A., Adewumi, I, M. O., \& Ladele, A. A. (1995). Relevance of standardization and grading in marketing of grains in Nigeria. Faculty of Agriculture, University of Illorin. Journal of Agro Search, 1(2), 129-134. view at Google scholar

Onoja, A. O., \& Herbert, B. C. (2012). Econometric evaluation of rice profitability determinants. Journal of Agricultural Extension and Rural Development, 4(5), 107.

UNCTAD (2007). Safety and quality of fresh fruit and vegetable: training manual for trainers. New York and Geneva.

Yisa, A. A. (2009). Cassava marketing: Option for sustainable agricultural development in Nigeria. Ozean Journal of Applied Sciences, 2(2), 175-182. view at Google scholar 